\title{
Drug treatment of hypertension
}

\author{
PAUL TURNER \\ From the Department of Clinical Pharmacology, St Bartholomew's Hospital, London
}

High blood pressure is a risk factor which has been shown in well documented studies to be significantly associated with excess morbidity and mortality. For example, the Framingham study (Kannel, Wolf, Verter, and McNamara, 1970) showed an increased risk of cardiovascular and cerebrovascular disease in initially asymptomatic persons whose initial pressures were $160 / 90 \mathrm{~mm} \mathrm{Hg}$ or greater. The worthwhileness of treating raised blood pressure has also been documented (Breckenridge, Dollery, and Parry, 1970), particularly in respect of cerebrovascular disease and renal impairment, although there appears to be little if any influence on the incidence of myocardial infarction. The underlying pathogenesis of so-called 'essential hypertension' is still unknown, and this probably explains in part the plethora of drugs presently available for its treatment. Furthermore, many of these drugs have more than one pharmacological action which could account for their antihypertensive effects and it is not possible, therefore, to extrapolate from their pharmacological properties to the underlying disease pathogenesis. Nevertheless, it is convenient to classify antihypertensive drugs according to their probable site of action.

In the broadest sense, antihypertensive drugs in common use may be divided into those that reduce sympathetic tone and so reduce cardiac output and/ or total peripheral resistance, and those which have direct vasodilator activity. They will now be considered in greater detail.

\section{Autonomic Ganglion-blocking Drugs}

These drugs were among the first potent effective antihypertensive agents to become available. Most of those which have been used therapeutically are quaternary ammonium compounds and their value is limited in two particular ways: (a) The highly ionized compounds, such as hexamethonium and pentolinium, are poorly absorbed from the gastrointestinal tract and have to be given parenterally for predictable effects. Pemipidine is better absorbed and may be given orally. (b) Both sympathetic and parasympathetic blockade are produced. Among the effects of parasympathetic blockade which are troublesome are diyness of the mouth from inhibition of salivary secretion, delayed gastric emptying, constipation, ileus, urinary retention and impotence, and impaired visual accommodation. Their action probably depends primarily on a fall in cardiac output and in total peripheral resistance from blockade of sympathetic ganglia. Little change in pressure is seen when recumbent, the main hypotensive effect being seen in the upright position, and postural hypotension frequently occurs. These drugs are now seldom used.

\section{Adrenergic Neurone-blocking Drugs}

Drugs which specifically block transmission in the postganglionic adrenergic neurone have the advantage over ganglion-blocking drugs that they do not produce parasympathetic blockade with its associated unpleasant effects. Adrenergic neurone blockade may be achieved in three ways:

1 Release of noradrenaline, the physiological neurotransmitter at sympathetic nerve endings by a nerve impulse, is prevented, although noradrenaline depletion does not occur. This appears to be the mode of action of guanethidine (Ismelin), bethanidine (Esbatal), and debrisoquine (Declinax) in oral therapeutic doses.

2 Noradrenaline is depleted so that there is none available for release by the nerve impulse. This is the probable mechanism of action of reserpine and the other Rauwolfia alkaloids.

3 Noradrenaline synthesis is impaired, or a false transmitter is substituted for noradrenaline with a weaker pressor action, so that sympathetic nerve activity results in a reduced response. This mechanism may account, in part, for the antihypertensive action of methyldopa (Aldomet).

Troublesome side-effects of treatment with these drugs are due to relative parasympathetic overactivity in the gut and urogenital system producing diarrhoea and interference with sexual function. Nasal congestion, fluid retention, and mental depression also occur. Methyldopa produces a positive antiglobulin test in $20 \%$ of patients but clinical haemolysis is rare.

As with the ganglion-blocking drugs, the anti- 
hypertensive effects of adrenergic-neurone-blocking drugs are chiefly seen in the erect position, and postural hypotension commonly occurs. One particular problem with guanethidine, bethanidine, and debrisoquine is that their action is prevented or reversed by tricyclic antidepressant drugs such as imipramine and amitriptyline (Simpson and WaalManning, 1971).

\section{Adrenergic Receptor-blocking Drugs}

Drugs which prevent or interfere with the release of noradrenaline from the adrenergic neurone such as those described above, block sympathetic activity irrespective of whether the nerve is supplying $\alpha$ or $\beta$ receptors, and the result is a general reduction in sympathetic activity. Drugs are now available which selectively block $\alpha$ adrenergic receptors and so reduce peripheral vascular resistance and others which block $\beta$-receptors, so reducing sympathetic tone on the heart and also reducing sympathetically induced bronchodilatation (Turner, 1974).

\section{$\alpha$ RECEPTOR-BLOCKING DRUGS}

$\alpha$-Adrenergic receptor-blocking drugs are useful in the management of phaeochromocytoma but have little place at present in other forms of hypertension. A possible exception is indoramin which appears to be of value in some hypertensive patients (White, Royds, and Turner, 1974), although sedation limits the dose range which can be used.

$\beta$ RECEPTOR-BLOCKING DRUGS

$\beta$-Adrenergic receptor blocking drugs have now established themselves in the management of essential hypertension (Simpson, 1974). Their mechanism of action is not yet clear but almost certainly involves a reduction in cardiac output. Effects on the central nervous system, a reduction in renin release by the kidney (see below), and modifications of baroreceptor activity may also be involved. There seems to be little difference in antihypertensive action between general $\beta$ receptor-blocking drugs without intrinsic sympathomimetic activity such as propranolol (Inderal) and sotalol (Beta-cardone), those with such activity such as pindolol (Visken) and oxprenolol (Trasicor), and cardioselective agents such as practolol (Eraldin).

The chief advantages of these drugs are that postural hypotension and impotence seldom occur with their use, and therefore, the patient's willingness to take the drugs is improved, particularly younger male patients. Their two principal adverse effects are cardiac failure and bronchial asthma. The first can often be treated with diuretics and digitalis. Although a cardioselective drug, such as practolol, may theoretically be safer in patients at risk of asthma, the danger of precipitating bronchospasm remains, and other forms of treatment should be used if possible. Rashes and dry red eye with corneal damage has been described following treatment with practolol.

\section{Drugs with Direct Action on Vascular Resistance}

THIAZIDE DIURETICS

The thiazide diuretics are widely used alone or in combination with other drugs in the management of mild and modest hypertension. Their action does not appear to depend simply on reduction in extracellular fluid volume and cardiac output and may involve a direct action on the blood vessel wall, reducing its reactivity in response to autonomic constrictor stimulation. If administered daily, supplementary potassium should be given. Excessive dosage may produce a reduction in circulating volume resulting in tachycardia, palpitations, and weakness, or even cardiovascular collapse. Diazoxide (Eudemine) is a thiazide derivative without diuretic activity, but with marked hyperglycaemic and hypotensive effects. Its use is generally restricted to intravenous bolus administration in acute hypertensive emergencies, particularly in patients with renal failure.

\section{OTHER ANTIHYPERTENSIVE AGENTS}

Clonidine (Catapres) is a potent antihypertensive drug whose mechanism of action is not yet understood. While there is evidence for a central action (see below), it has peripheral effects on blood vessels, reducing their response both to the constrictor effect of noradrenaline and to the dilator action of isoprenaline (Zaimis and Hanington, 1969; Coupar and Kirby, 1972). This may be the basis of its usefulnes in some patients with migraine. Like some of the adrenergic neurone-blocking drugs, its action can be blocked by tricyclic antidepressant drugs (Briant, Reid, and Dollery, 1973).

Hydrallazine (Apresoline) is a potent antihypertensive agent, its predominant action being a generalized relaxation of arteriolar smooth muscle. It has a high incidence of undesirable effects, particularly tachycardia and palpitations, but these can be markedly reduced by the combined use of a $\beta$ adrenergic blocking drug, which also allows a smaller dose of hydrallazine. More dangerous is the production of a hypersensitivity reaction with arthropathy, and, rarely, a syndrome indistinguishable from disseminated lupus erythematosus. Nevertheless, interest in vasodilator drugs, including hydrallazine, has revived in recent years (British Medical Journal, 1973). 
Prazosin (Hypovase) has recently been introduced and is being evaluated. It produces a reduction in total peripheral resistance due, it is thought, to direct relaxation of arteriolar smooth muscle (Stokes and Weber, 1974).

Sodium nitroprusside, administered by carefully monitored intravenous infusion, has a direct relaxant effect on vascular musculature. The effect is immediate both in onset and offset. It is, therefore, of particular value in the management of very severe hypertension or its acute complications. Long-term effects are due to the accumulation of thiocyanate to which it is converted, and serum levels of the latter should be measured at frequent intervals (Verner, 1974).

\section{Other Possible Mechanisms}

INHIBITION OF RENIN SECRETION

Investigations by Bühler, Laragh, Baer, Vaughan, and Brunner (1972) suggested that the effectiveness of propranolol in reducing blood pressure in hypertensive patients was closely related to their plasma renin activity, patients with a high renin level showing a uniformly satisfactory response to accepted $\beta$-blocking doses of propranolol, patients with normal levels showing less consistent though still marked responses, and patients with low renin levels showing uniformly ineffective responses. The fall in pressure in the high and normal renin groups correlated well with the fall in plasma renin which occurred. While this offered an interesting and theoretically attractive mechanism for the antihypertensive action of $\beta$-blocking drugs, more recently other investigators, using a larger number of these agents, have not been able to confirm the close relationship between antihypertensive effects and changes in plasma renin activity and urinary aldosterone excretion (Stokes, Weber, and Thornell, 1974).

CENTRAL MECHANISM

There is increasing evidence that at least part of the therapeutic activity of many antihypertensive drugs is mediated through central nervous system mechanisms. This would not be surprising in view of the side effects upon the central nervous system of drugs such as reserpine, methyldopa, and clonidine. Animal experiments have provided strong evidence for central adrenergic control of blood pressure, with opposing $\alpha$ and $\beta$ receptor actions. Stimulation of central $\alpha$ receptors in cats produces a fall in heart rate and blood pressure while stimulation of $\beta$ receptors increases heart rate and blood pressure (Day and Roach, 1974). Destruction of central noradrenergic pathways with 6-hydroxydopamine produces changes in blood pressure consistent with these findings (Lewis, Rawlins, and Reid, 1974). It could be postulated that $\beta$-blocking drugs might reduce blood pressure, in part at least, by blocking these central $\beta$-receptors (Dollery, Lewis, Myers, and Reid, 1973), Clonidine has been shown to act as an $\alpha$ receptor agonist on single neurones in the central nervous system, and this could explain at least part of its action (Anderson and Stone, 1974). The so-called false transmitter $\alpha$-methyl-noradrenaline, which accumulates in adrenergic nerves following treatment with methyldopa, has $\alpha$ receptor agonist properties similar to noradrenaline (Coupar and Turner, 1970), and it could be postulated that stimulation of central $\alpha$ receptors by $\alpha$ methylnoradrenaline might be responsible for at least part of the antihypertensive action of methyldopa (Andén, Butcher, and Engel, 1970).

\section{Treatment Regimes}

While recognizing the need to treat any patient with a blood pressure above the normal range for his or her age and sex, it is important to remember that such treatment may have to continue for many years, and that the patient's cooperation is, therefore, 8 essential. For many people, quality of life is as, if not more, important than its extension by drug treatment, and the mildest form of treatment, with? the least unpleasant side effects, which will produce a satisfactory fall in blood pressure, should be used.

\section{MILD-MODERATE HYPERTENSION}

In patients with only a modest elevation of pressure and little or no evidence of cardiac, vascular, or renal impairment, a thiazide diuretic or a $\beta$-adrenergic-receptor-blocking agent is usually the first drug of choice. If a satisfactory response is not obtained with either of those above mentioned, combined treatment may be used. It may be necessary to increase the dose of the $\beta$-blocking drug to high levels before adequate control is obtained, and the pressure may continue to fall slowly for several weeks after a change in dose.

\section{MODERATE-SEVERE HYPERTENSION}

The $\beta$-receptor blocking drugs may be of value in these patients, but because of the time taken to reach a satisfactory response, it may be desirable to use a more quickly acting drug, particularly in patients with evidence of cardiovascular or renal impairment. Adrenergic-neurone-blocking drugs, vasodilator agents, or clonidine are widely used in these circumstances. 


\section{SEVERE HYPERTENSION AND HYPERTENSIVE CRISIS}

These conditions require urgent treatment to reduce blood pressure, and intravenous diazoxide or sodium nitroprusside or subcutaneous pentolinium may be used in the most urgent cases. Parenteral methyldopa or reserpine may be given in less urgent circumstances. Intravenous guanethidine may produce an initial increase in pressure before its antihypertensive effect is established, which limits its usefulness in this condition.

The management of essential hypertension is still far from ideal, and it is to be hoped that better understanding of its pathogenesis will lead to the development of more rational and effective treatment which, because of its selectivity of action, will be more easily tolerated by the patient.

References

Anden, N., Butcher, S. G., and Engel, J. (1970). Central dopamine and noradrenaline receptor activity of the amines formed from m-tyrosine, a methyl-m-tyrosine and a methyldopa. J. Pharm. Pharmacol., 22, 548-550.

Anderson, C., and Stone, T. W. (1974). On the mechanism of action of clonidine effects on single central neurones. Brit.J. Pharmacol., 51, 359-365.

Breckenridge, A., Dollery, C. T., and Parry, E. H. O. (1970). Prognosis of treated hypertension. Quart. J. Med., 39, 411-429.

Briant, R. H., Reid, J. L., and Dollery, C. T. (1973). Interaction between clonidine and desipramine in man. Brit. med. J., 1, 522-523.

British Medical Journal (1973). Editorial. New vasodilator drugs for hypertension. Brit. med. J., 4, 185-186.
Bühler, F. R., Laragh, J. H., Baer, L., Vaughan, E. D. Jr., and Brunner, H. R. (1972). Propranolol inhibition of renin secretion. New Engl. J. Med., 287, 1209-1214.

Coupar, I. M., and Kirby, M. J. (1972). The effect of clonidine on human isolated smooth muscle. Europ. J. Pharmacol., 17, 50-58.

Coupar, I. M., and Turner, P. (1970). Relative potencies of some false transmitters on isolated human smooth muscle. Brit. J. Pharmacol., 38, 463P-464P.

Day, M. D., and Roach, A. G. (1974). Central $\alpha$ and $\beta$ adrenoceptors modifying arterial blood pressure and heart rate in conscious cats. Brit. J. Pharmacol., 51, 325-333.

Dollery, C. T., Lewis, P. J., Myers, M. G., and Reid, J. L. (1973). Central hypotensive effects of propranolol in the rabbit. Brit. J. Pharmacol., 48, 343P.

Kannel, W. B., Wolf, P. A., Verter, J., and McNamara, P. M. (1970). Epidemiologic assessment of the role of blood pressure in stroke: the Framingham study. J. Amer. med. Ass., 214, 301310.

Lewis, P. J., Rawlins, M. D., and Reid, J. (1974). The effects of intraventricular 6-hydroxydopamine on body temperature and arterial blood pressure in cats and rabbits. Brit. J. Pharmacol., 51, 207-212.

Simpson, F. O. (1974). $\beta$-Adrenergic receptor blocking drugs in hypertension. Drugs, 7, 85-105.

Simpson, F. O., and Waal-Manning, H. J. (1971). Hypertension and depression: interrelated problems in therapy. $J$. roy. Coll. Physns. Lond., 6, 14-24.

Stokes, G. S., Weber, M. A., and Thornell, I. R. (1974). $\beta$-blockers and plasma renin activity in hypertension. Brit. med. J., 1, 60-62.

Stokes, G. S., and Weber, M. A. (1974). Prazosin (Hypovase): preliminary report and comparative studies with other antihypertensive agents. Brit. med. J., 2, 298-300.

Turner, P. (1974). Drugs and the autonomic nervous system. Presc. J., 14, $41-47$.

Verner, I. R. (1974). Sodium nitroprusside: theory and practice. Postgrad. med. J., 50, 576-581.

White, C. de B., Royds, R., and Turner, P. (1974). Some clinical pharmacological studies with indoramin with observations on its therapeutic usefulness. Postgrad. med. J., 50, 729-733.

Zaimis, E., and Hanington, E. (1969). A possible pharmacological approach to migraine. Lancet, 2, 298-300. 